${ }^{2}$ Boger WP. Fulminating meningococcemia. Demonstration of intracellular and extracellular meningococci in direct smears of the blood. N Engl J Med 1944;231:385-7.

${ }^{3}$ Boone JT, Hall WM. Meningococcal septicaemia with report of case showing organisms in direct blood smear. US Nav M Bull 1935;33:446-51.

\section{Prevalence of atypical naevi in a general pathology practice}

I read with interest the recent article by Seywright $e t$ al $^{1}$ on a proposed subclassification of "dysplastic naevi" based on architectural and cytological atypia. Their results showed that out of 100 melanocytic naevi reviewed, 38 were regarded as being atypical-that is, exhibited either architectural atypia alone or in combination with cytological atypia. Such a high prevalence in this series most likely reflects the source of the material, which was the university department of dermatology, which has a referral centre for pigmented lesions and, indeed, as the authors correctly pointed out, that such findings should not be regarded as representative of the incidence of atypical naevi in the Scottish population as a whole.

Prompted by these results I decided to review the histology of 114 consecutive melanocytic naevi reported in 1985 from a

general pathology practice consisting of two consultants, one of whom has a special interest in dermatopathology. The Table illustrates the main findings using the terminology suggested by Seywright et al in their article.

From these results it can be seen that about $6 \%$ of all the melanocytic naevi in this series were in the atypical category. This figure compares favourably with those of previous reports in which the prevalence of "dysplastic naevi" in the general population was estimated to be about $5 \% .^{2-4}$

R NORTON

Department of Pathology, Southern General Hospital. Glasgow, Scotland G51 4TF

References

${ }^{1}$ Seywright MM, Doherty V, MacKie RM. Proposed alternative terminology and subclassification of so called "dysplastic naevi”. J Clin Pathol 1986;39:189-94.

${ }^{2}$ Crutcher WA. Sagebiel RW. Prevalence of dysplastic naevi in a community practice. Lancet 1984;1:729.

${ }^{3}$ Rhodes AR, Sober AS, Mihm MC, Fitzpatrick TB. Possible risk factors for primary cutaneous malignant melanoma. Clin Res 1980;28:252.

${ }^{4}$ Sheiber A, Milton GW, McCarthy MH, Shaw H. Clinical features, prognosis and incidence of multiple primary cutaneous malignant melanoma. Aust NZ J Surg 1981;51:386.

\begin{tabular}{lllll}
\hline $\begin{array}{l}\text { Total No of melanocytic } \\
\text { naevi }\end{array}$ & Banal naevi & Atypical naevi & $\begin{array}{l}\text { Architectural } \\
\text { atypia }\end{array}$ & $\begin{array}{l}\text { Architectural and } \\
\text { cytological atypia }\end{array}$ \\
\hline 114 & 107 & 7 & 6 & 1 \\
\hline
\end{tabular}

\section{Book Reviews}

Pathology Annual 1986. Part I. Series eds SC Sommers, PP Rose, RE Fechner. (Pp 358; £69.55.) Prentice Hall. 1986. ISBN 0-8385-7772-5.

This volume brings an era to an end; that of Dr Sommers who fathered, conceived, and delivered the series for 20 years. His stated philosophy of bringing contributions from mature and experienced professionals to the public in a form that was understandable by all has largely been fulfilled, and we owe him a gratitude. The present Annual fairly reflects the trends set in the past. The choice of topics is eclectic, if at times uneven, but there is much to interest many, though not necessarily all. First, we have a book within a book, the extensive review of head and neck cancers, complete with diagrams, charts, statistics, and backed by a mass of detailed and up to date information. The chapters on endocrine cell hyperplasias, divergent differentiation in neoplasms, and diversity of osteosarcomas have a similar message: there is more to it than meets the eye. Tumour host interactions, papilloma virus induced neoplasia, midline granuloma syndrome, atypical mycobacteria, the vexation of mesothelioid-hyperplasia $v$ neo- plasia, aspiration cytology of the liver are all useful, if not definitive accounts. We also have the usual literary contribution, this time on infanticide in 18th century England. The price for the book, however, remains high.

PP ANTHONY

Guides to Clinical Aspiration Biopsy. Prostate. Tilde S Kline. (Pp 189; £43.75.) Williams \& Wilkins. 1985.

This monograph gives a full account of the role of aspiration biopsy cytology in the diagnosis of prostatic pathology. The clinical value of the method in primary diagnosis and in the management of established malignant disease is emphasised, as is the importance of clinical cooperation in the skilled collection technique. The cytological appearances and the pitfalls in diagnosis are described and illustrated. Although the photomicrographs are generally of a satisfactory standard, in some chapters they seem to be rather repetitive. A chapter on immunocytochemistry has presumably been included because of the contribution the technique can make to the diagnosis of metastatic prostatic disease. A section devoted to the cytology of "dysplasia" is somewhat surprising as this controversial diagnosis cannot contribute to clinical care. Although this book makes no further important contribution to the accounts given in the existing texts, particularly the Scandinavian ones, it might prove useful in departments with a special interest in prostatic pathology.

HELENA E HUGHES

Subcellular Taxonomy. An Ultrastructural Classification system with diagnostic applications. AIC McLay, PG Toner. (Pp 80; $\$ 41.50$ US and Canada.) Hemisphere Publishing Corporation. 1985. ISBN: 0-89116-293-3.

This volume attempts to overcome the shortcomings of SNOP and SNOMED for the ultrastructural pathologist, providing a coding system that should occupy the T-YX section of SNOMED. The problems of ultrastructural coding in diagnostic work are considered in the introduction, and as they are defined in that section, seem to be adequately resolved here. As entertainment, the test is less compelling than HB Morton's List of Huntingdonshire Cabmen, but when used to classify six ultrastructurally studied biopsies it proved effective and simple to use.

CL BERRY 